Department of Medicine

Beth Israel Hospital

Boston, Massachusetts 02215, USA

\section{ELAZER R. EDELMAN \\ Department of Medicine \\ Brigham and Women's Hospital \\ Harvard Medical School}

Boston, Massachusetts 02215, USA

Department of Health, Science and Technology

Massachusetts Institute of Technology

Cambridge, Massachusetts 02139, USA

Stein replies - Simons et al. raise some interesting points, but, I believe, obscure others. I did not state, as claimed, that I believe that the "in vitro and in vivo antiproliferative effects of several different antisense oligonucleotides on smooth muscle cells may be due to the binding/inhibition of bFGF by the presence of a four $G$ repeat sequence in these agents". Rather, I confined my comments to the antisense c-myb phosphorothioate oligodeoxynucleotide. My view has been heavily influenced by the data of Burgess et al. ${ }^{9}$ who, after examining both the antisense $c-m y b$ and $c-m y c$ oligomers, could find little or no evidence for sequence-specific target inhibition. The conclusion of these authors was that in both cases, inhibition was based on the presence of a G-quartet. Others have also shown a lack of specificity for the c-myb oligomer in rat, dog and human aortic smooth muscle cells in vitro and in neointimal proliferation in the rat carotid model ${ }^{10}$. Furthermore, it has also been shown that the non-sequence-specific 28-base homopolymer of cytidine ( $\mathrm{SdC28}$ ) is a very effective inhibitor of neointimal proliferation in the rat carotid model (W. Wang et al., personal communication). In aggregate, the data appear to indicate that, at best, the established fact of phosphorothioate oligodeoxynucleotide inhibition of neointimal proliferation occurs as the sum of sequence specific plus non-sequence-specific processes. The argument then devolves to the question of to what extent each process is present. I have little doubt that the relative contribution of each of the processes is different in each system tested, and is highly dependent on phosphorothioate oligomer concentration, length and sequence.

Next, the fact that an anti-bFGF antibody does not suppress neointimal formation over a two-week period, as stated by Simons et al., may not be relevant, because the pharmacokinetic and tissue adsorptive properties of a phosphorothioate oligodeoxynucleotide will be different from those of an antibody. Furthermore, I nowhere stated, nor do I believe, that interaction with bFGF is the only non-sequence-specific method by which phosphorothioates inhibit neointimal formation. Interaction with PDGF may well be involved, in addition to interactions of the oligomers with cell surface receptors. These interactions are currently being extensively explored. The pleiotropic properties of phosphorothioate oligomers, in my opinion, lead to their high antiproliferative activity. It is thus not surprising that treatment of cells with phosphorothioate oligomers produces the same growth inhibitory effects as specific downregulation of $c-m y b$ function. Thus, inhibition of cellular growth and related phenomena cannot be cited as being demonstrative of an antisense mechanism of action.

\section{C.A. STEIN}

Columbia University

College of Physicians and Surgeons

New York, New York 10032, USA

1. Stein, C.A. Does antisense exist? Nature Med. 1,
1119-1121 (1995).

2. Abe, J. et al. Suppression of neointimal smooth muscle cell accumulation in vivo by antisense cdc2 and cdk2 oligonucleotides in rat carotid artery. Biochem. Biophys. Res. Commun. 198, 16-24 (1994).

3. Edelman, E.R., Simons, M., Sirois, M.G. \& Rosenberg, R.D. C-myc in vasculoproliferative disease. Circ. Res. 76, 176-182 (1995).

4. Simons, M., Edelman, E.R. \& Rosenberg, R.D. Antisense PCNA oligonucleotides inhibit intimal hyperplasia in a rat carotid injury model. f. Clin. Invest. 93, 2351-2356 (1994).

5. Morishita, R. et al. Single intraluminal delivery of antisense cdc2 kinase and proliferating-cell nuclear antigen oligonucleotides results in chronic inhibition of neointimal hyperplasia. Proc. Natl. Acad. Sci. USA 90, 8474-8478 (1993).

6. Sirois, M., Simons, M. Edelman, E.R., Kuter, D.J. \& Rosenberg, R.D. Platelet release of platelet-derived growth factor is required for intimal hyperplasia in rat vascular injury model. Circulation 90, I-511 (1994).

7. Lindner, V. \& Reidy, M.A. Proliferation of smooth muscle cells after vascular injury is inhibited by an antibody against basic fibroblast growth factor. Proc. Natl. Acad. Sci. USA 89, 3739-3743 (1991).

8. Husain, M. et al. Dominant negative c-myb constructs lower intracellular calcium levels and slow cell cycle progression in vascular smooth muscle cells. Circulation 92, I-299 (1995).

9. Burgess, T. et al. The antiproliferative activity of $c-m y b$ and c-myc antisense oligonucleotides in smooth muscle cells is caused by a nonantisense mechanism. Proc. Natl. Acad. Sci. USA 92, 4051-4055 (1995).

11. Villa, A. et al. Effects of antisense c-myb oligonucleotides on vascular smooth muscle cell proliferation and response to vessel wall injury. Circ. Res. 76, 505-513 (1995).

\title{
Thalidomide neuropathy
}

Neuropathy after the administration of thalidomide is a very serious complication. It is frequently irreversible and, if sensory action potentials are recorded, can be detected in at least $23 \%$ of patients given the drug ${ }^{1}$. This complication is not mentioned by Diane Gershon in her news item $^{2}$. Correspondence between Francis Kelsey of the FDA and Richardson-Merrell in 1961 indicates that it was the peripheral nerve side-effects that determined her decision not to license the drug in the USA $^{3}$. The UK Committee on the Safety of Medicines has recently issued strict guidelines about the use of the drug in the $\mathrm{UK}^{4}$. These include a warning to the patients that peripheral nerve damage can occur which may be "severe and irreversible." Sensory nerve action potentials should be recorded before the start and be repeated during the course of treatment. The guidelines to the patients state "should you develop pins and needles you must stop thalidomide immediately". It is not clear whether the manufacturers, Andrulis Pharmaceuticals and Celgene, mention in the information provided with the supply of thalidomide, whether the drug causes a neuropathy, and whether the physicians administering thalidomide specifically warn the patients about this side effect.

Although the drug has been used in the management of erythema nodosum leprosum for over 25 years, thalidomide neuropathy has not been excluded in leprosy patients ${ }^{5}$. Furthermore, as revealed by the media, some 49 children in Brazil have developed phocomelia as a result of the mother's taking thalidomide during pregnancy ${ }^{6}$.

\section{C.L. CRAWFORD}

Department of Anatomy

Charing Cross and Westminster Medical School Fulham Palace Road, London W6 8RF, UK

1. Ochonisky, S., Verroust, J., Bastuji-Garin, S., Gheradi, R. \& Revuz J. Thalidomide neuropathy incidence and clinicoelectrophysiologic findings in 42 patients. Arch. Dermatol. 130, 66-69 (1994).

2. Gershon, D. Finding new uses for thalidomide. Nature Med. 1, 1230 (1995).

3. Sjostrom, H. \& Nilsson, R. Thalidomide and the Power of the Drug Companies. 112-130 (Penguin Books, Harmondsworth, Middlesex, England 1972).

4. Powell, R.J.\& Gardner Medwin, J.M.M. Guideline for the clinical use and dispensing of thalidomide. Postgrad. Med. I. 70, 901-904 (1994).

5. Crawford, C.L. Use of thalidomide in leprosy. Adverse Drug React. Toxicol. Rev. 13, 177-192 (1994).

6. Thalidomide: The drug that came back. First Tuesday; June 1, Yorkshire Television (1993). 